\title{
Personalized tourniquet pressure may be a better choice than uniform tourniquet pressure during total knee arthroplasty: a meta- analysis of randomized-controlled trials.
}

\author{
Changjiao Sun ( $\square$ suncjdoctor@163.com ) \\ Xin Yang \\ Peking University First Hospital \\ Qi Ma \\ Beijing Tsinghua Changgung Hospital \\ Peng Yu \\ Wuhan University of Science and Technology hospital \\ Xu Cai \\ Beijing Tsinghua Changgung Hospital \\ Yonggang Zhou \\ Chinese PLA General Hospital
}

Beijing Tsinghua Changgung Hospital, School of Clinical Medicine,Tsinghua University https://orcid.org/0000-0001-7487-8025

\section{Research article}

Keywords: total knee arthroplasty, Personalized tourniquet inflation pressure, systolic blood pressure, Limb occlusion pressure

Posted Date: April 1st, 2021

DOI: https://doi.org/10.21203/rs.3.rs-376700/v1

License: (c) (i) This work is licensed under a Creative Commons Attribution 4.0 International License. Read Full License 


\section{Abstract}

Background: Pneumatic tourniquets are widely used in total knee arthroplasty (TKA). Some surgeons prefer a uniform tourniquet inflation pressure (UTIP)for all patients; others use personalized tourniquet inflation pressures (PTIP) based on systolic blood pressure (SBP) and limb occlusion pressure(LOP). However, no consensus exists regarding the optimal mode of inflation pressure during TKA. This review aimed to appraise if personalized tourniquet inflation pressures are better than uniform tourniquet inflation.

Methods: The databases (Web of Science区Embase『PubMed『Cochrane Controlled Trials Register, $₫$ Cochrane Library $\square$ Highwire $\llbracket C B M \square C N K I \square V I P \square$ Wanfang) were searched on March 2021 to systematically identify and screen the literature for randomized controlled trials (RCTs) involving PTIP and UTIP during total knee arthroplasty.

Results: Thirteen randomized controlled trials, involving 1204 TKAs (1201 patients) were included in the systematic review. The metaanalysis identified a trend toward less Visual Analogue Scale (VAS) score at rest with PTIP group at one day $\mathbb{P}=0.002 \mathbb{} \otimes 2-3$ day $\mathbb{P}=0.01 \rrbracket$, and less VAS score at activity 1 day ( $\mathrm{P} \otimes 0.0001$ ),2-3 days after the operation ( $\mathrm{P} \otimes 0.00001$ )and discharge (P囚0.0001). No significant difference was found between the groups in terms of VAS score at rest when discharge $(P=1.0)$. We also found no significant difference in terms of

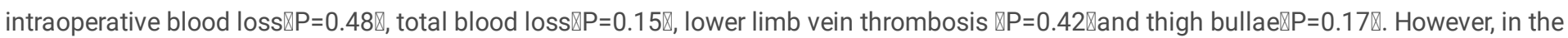
PTIP group, we found a significant higher Hospital for Special Surgery (HSS) score $\otimes P=0.007 \rrbracket$,broader knee Range of motion(ROM) $\triangle P=0.02 \rrbracket$, less rate of thigh ecchymosis $\ P=0.00001$ and shorter thigh circumference at one day $(P=0.006), 2-3$ day $(P=0.0005)$, and discharge $(P=0.02)$.

Conclusion: PTIP provides a similar bloodless surgical field compared with the conventional UTIP. Furthermore, PTIP provides less pain intensity, thigh circumference, rate of thigh ecchymosis, higher HSS and better initial recovery of knee flexion in total knee arthroplasty. Therefore, we recommend using a PTIP method during TKA. More adequately powered and better-designed randomized controlled trials $\triangle R C T s \llbracket$ studies with long-term follow-up are required to produce evidence-based guidelines regarding the PTIP method.

\section{Background}

Pneumatic tourniquets that are used in total knee arthroplasty (TKA) may lead to soft tissue damage, including the skin, vessels, muscles, nerves, and fibrinolytic activity due to unnecessarily excessive inflation pressure[1-4]. However, many orthopedic surgeons use it. A study of the American Association of Hip and Knee Surgeons found that approximately 95\% of surgeons used tourniquets during TKA[5].

The tourniquet can provide a clear bloodless field, which potentially reduces intraoperative blood loss, operative time and better prepares the cement-bone interface, despite the possible adverse effects associated with its use during total knee arthroplasty (TKA)[6]. The tourniquet use is almost indispensable in orthopedic practice. Although a lot of procedures employ the use of a tourniquet, there is still a lack of evidence-based guidelines of standard practice regarding optimal inflation pressures[7-9]. While some prefer a uniform tourniquet inflation pressure(UTIP) for all patients[10-12], others use personalized tourniquet inflation pressures (PTIP), which based on systolic blood pressure $(\mathrm{SBP})[3,13,14]$ or limb occlusion pressure (LOP). This study aimed to compare the effects of the PTIP with conventional UTIP on rehabilitation outcomes in TKA patients.

\section{Methods}

Our meta-analysis was registered on PROSPERO (International prospective register of systematic reviews), and the registration number was CRD42020168432. We assessed the quality of the included studies according to the items recommended in Cochrane Collaboration (Revman 5.3; http://handbook.cochrane.org/), and PRISMA (Preferred Reporting Items for Systematic Reviews and Meta-analyses) guidelines

\section{Search strategy}

We identified relevant randomized controlled trials involving PTIP or conventional UTIP in total knee arthroplasty in electronic databases,

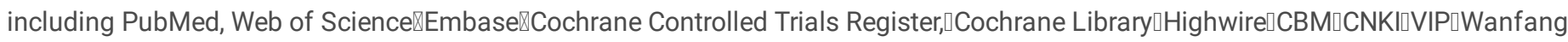
database, up to March 2021. The keywords included "total knee arthroplasty," "total knee replacement," " tourniquet," "pressure" in conjunction with Boolean operators "AND" or "OR." Review Manager Software was used to perform our meta-analysis.

\section{Inclusion criteria}

The inclusion criteria were: 1. The intervention was PTIP, based on SBP or LOP in TKA; 2 . The comparator was the UTIP based on surgeon experience;3. Randomized controlled trial studies; 4 . The outcomes are intraoperative blood loss, total blood loss, Visual Analogue Scale 
(VAS) score, Hospital for Special Surgery (HSS) score, knee range of motion(ROM), thigh circumference, complication rates including lower limb vein thrombosis, thigh bullae, and thigh ecchymosis; 5 . The follow-up rate was at least $80 \%$. 6 . At least one outcome was included in the study;

The exclusion criteria were as follows:1. Observational studies;2. non-RCTs; 3. The included studies have insufficient outcome data.

\section{Data extraction process}

Two reviewers independently extracted the available data from each study. The primary data were based on the following: first author, year of publication, country, number of TKAs and participants, age, gender, BMI, the primary indication for TKA, prosthesis, anesthesia, operation time, mean tourniquet time, mean inflation pressure, practices of tourniquet pressure, the time for loosening the tourniquet. The primary outcome consisted of Intraoperative blood loss, total blood loss, VAS score, HSS score, complications such as lower limb vein thrombosis, thigh bullae, and thigh ecchymosis. Secondary outcomes included knee ROM and thigh circumference.We resolved the disagreements by discussion to reach a consensus.

\section{Quality Assessment}

We used the Cochrane risk of bias tool to assess the risk of bias in the RCTs and determine whether biases might have affected the results.

\section{Statistical Analysis}

Review Manager Software for MAC (version 5.3) was used to perform the meta-analysis. The $Q$ test and $I^{2}$ were used to evaluate the heterogeneity between studies. The random-effects model was in the place of the fixed effects model for heterogeneity test, $\mathrm{P}$ values $\leq .1$ or $\mathrm{I}^{2} \geq 50 \%$. The mean difference (MD) or standard mean difference (SMD) was used to assess continuous outcomes such as VAS, blood loss, HSS, knee ROM, and thigh circumference with a 95\% confidence interval (Cl). We used Relative risks with a $95 \% \mathrm{Cl}$ to assess dichotomous outcomes such as rate of lower limb vein thrombosis, thigh bullae, and thigh ecchymosis. We considered the results as a statistically significant difference when $P$ values were less than 0.05

\section{Results}

\section{Search results}

The detailed literature screening process is shown as the PRISMA flow diagram in Fig. 1. The literature search identified 489 citations. Of these, we removed 330 duplicates. Upon reviewing the titles and abstracts of the 159 remaining articles, we excluded 144 papers according to the inclusion criteria and retrieved the full text of 13 articles. Finally, we identified 1204 TKAs (1201 patients) assessed in 13 randomized controlled trials[15-27] We presented the detailed baseline characteristics in table 1 and tourniquet intervention information in Table 2. All the papers were published in English and Chinese between the years 2005 and 2021.

\section{Risk of Bias assessment}

The risk of bias summary and bias graph for RCTs is shown in Figs. 2 and 3. The correct randomization and sufficient allocation concealment were adequately described in ten studies. The blinding of outcome assessment was described in thirteen studies, and the blinding of participants and personnel was described in three studies. Each study retained complete outcome data and avoided selective reporting. Other potential biases of all studies can't be ignored. Therefore, we rated them as having an unclear risk of other bias. As a result, the included studies' overall quality was considered adequate (Fig. 2 and 3).

\section{Pooled analysis of blood loss between the PTIP group and UTIP group}

Patients in both groups experienced similar intraoperative blood loss (MD=-1.41, 95\% Cl [-5.36,2.54], P=0.48 Fig.4) and total blood loss (MD=-87.23, 95\% Cl [-206.86,32.40], P=0.15 Fig.4).

\section{Pooled analysis of VAS between PTIP group and UTIP group}

we were able to detect a significantly lower VAS at rest 1 day after operation(MD=-1.23, 95\% $\mathrm{Cl}[-2.03,-0.44], \mathrm{P}=0.002 \mathrm{Fig} .5), 2-3$ days after operation(MD=-1.02, 95\% Cl [-1.8,-0.23], P=0.01 Fig. 5) and lower VAS at activity 1 day after operation(MD=-0.69, 95\% Cl [-1.02,-0.37], $P \llbracket 0.0001$ Fig. 5) ,2-3 days after operation (MD=-1.18, 95\% Cl [-1.49,-0.87], Pख0.00001 Fig. 5)and discharge (MD=-2.29, 95\% Cl [-3.33,-1.25], $\mathrm{P} \otimes 0.0001 \mathrm{Fig}$. 5 ) in patients with personalized pressure group. The results of the meta-analysis showed that patients in both groups experienced similar VAS at rest when discharge from hospital (MD=-0.00, 95\% $\mathrm{Cl}[-0.74,0.74], \mathrm{P}=1.0$ Fig. 5). 
Pooled analysis of complication rates between PTIP group and UTIP group

Our results showed that patients in both groups experienced similar rates of lower limb vein thrombosis $(\mathrm{MD}=-0.03,95 \% \mathrm{Cl}[-0.1,0.04]$, $\mathrm{P}=0.42$, Fig. 6) and thigh bullae ( $\mathrm{MD}=-0.08,95 \% \mathrm{Cl}[-0.17,0.02], \mathrm{P}=0.1 \mathrm{Fig} .6)$, however we also detect a significantly lower rate of thigh ecchymosis (MD=-0.19, 95\% Cl [-0.24,-0.13], $\mathrm{P} \otimes 0.00001 ;$ Fig. 6)in patients with personalized pressure group.

\section{Pooled analysis of HSS between PTIP group and UTIP group}

Our results showed that patients in personalized pressure group experienced higher HSS scores (MD=1.90, 95\% Cl [0.51,3.29], P=0.007 Fig. 7).

\section{Pooled analysis of ROM between PTIP group and UTIP group}

We detected a significantly better knee $\mathrm{ROM}(\mathrm{MD}=3.82,95 \% \mathrm{Cl}[0.58,7.06], \mathrm{P}=0.02 ; \mathrm{Fig}$. 8) in patients with personalized pressure group.

\section{Pooled analysis of thigh circumference between PTIP group and UTIP group}

We detected a significantly shorter thigh circumference 1 day after operation( $\mathrm{MD}=-3.08,95 \% \mathrm{Cl}[-5.28,-0.88], \mathrm{P}=0.006$; Fig. 9),3day after operation( $\mathrm{MD}=-3.05,95 \% \mathrm{Cl}[-4.78,-1.32], \mathrm{P}=0.0005$; Fig. 9$)$ and 5 day after operation ( $\mathrm{MD}=-0.51,95 \% \mathrm{Cl}[-0.95,-0.07], \mathrm{P}=0.02$; Fig. 9) in patients with personalized pressure group.

\section{Discussion}

Although clinical efforts and advances in tourniquet technology have resulted in the use of lower inflation pressures, there was no metaanalysis comparing the effects of PTIP with UTIP on rehabilitation outcomes and postoperative complications. Our meta-analysis is the first meta-analysis to compare the impact of PTIP with conventional UTIP during TKA

The current meta-analysis's main finding was that both PTIP and conventional UTIP ensure equal blood loss in total knee arthroplasty. No significant difference was observed between the groups in terms of rate of lower limb vein thrombosis, and thigh bullae. However, in patients using a tourniquet with PTIP, we found a significant reduction in postoperative pain, thigh circumference, rate of thigh ecchymosis, higher HSS and a better initial recovery of knee flexion.

The present work analysis was not able to identify any differences between the two groups in the case of intraoperative blood loss and total blood loss. These findings mean PTIP would provide a bloodless surgical field comparable to conventional UTIP.

Immediate postoperative pain relief following TKA is crucial in facilitating early recovery. We were able to detect a significantly lower pain intensity within three days after operation both at rest and during mobilization in patients with PTIP group. We also identified a significantly lower pain intensity at the activity when patients were at discharge; however, we couldn't identify any difference of pain intensity at rest when patients left the hospital. An explanation for the increased pain in the early postoperative period with conventional uniform pressure group could be direct higher pressure on the surrounding soft tissues due to the tourniquet. In our study, the pressure of the PTIP is lower than the conventional UTIP group. Worland et al.[28] showed an essential correlation between tourniquet pressure and thigh pain in the immediate postoperative period. We thought that the PTIP lowers pain levels while increasing patients' adherence to rehabilitation, which resulted in earlier restoration in functions.

In patients using a tourniquet with PTIP, we found a significant reduction in thigh circumference. We think the reason may be due to less stress on the thigh muscles in the PTIP group.

Knee flexion ROM is often used to evaluate short-term effectiveness. Besides, discharge from the hospital is dependent on the mobility of patients following TKA. The PTIP group documented a significantly higher postoperative ROM. It may be related to using a conventional UTIP with higher tourniquet pressure that causes some temporary loss of flexibility in the tight thigh muscles. The PTIP group also reveal a higher HSS score. The reason may be less pain, more knee ROM in the PTIP group.

As for complications, all studies did not experience major significant complications such as symptomatic PE, thigh necrosis, nerve palsy, or delayed rehabilitation. We found no significant difference between groups regarding the rate of lower limb vein thrombosis and thigh bullae. However, in patients using a tourniquet with personalized tourniquet inflation, we found a significant reduction in the quality of thigh ecchymosis. It is possible to achieve functional benefits with decreasing some complications related to the tourniquet and to have the advantages as with the personalized tourniquet application. 
The pressure for safe tourniquet use remains controversial, and no strict guidelines have been established. Most of the orthopedic surgeons routinely apply fixed tourniquet pressure in TKA based on individual experiences. It was very convenient to choose the fixed pressure value. However, it did not take patients' actual individual situation into account, so the selected pressure values were mostly on the high side. Some researchers suggested that upper limb pressure in an adult is 250 to $300 \mathrm{~mm} \mathrm{Hg}$, and lower limb pressure is 350 to $500 \mathrm{~mm} \mathrm{Hg}[29]$. A higher tourniquet pressure ensures the reliable function of the tourniquet; however, it may lead to a higher incidence of complications. The pressures higher than $350 \mathrm{mmHg}$ on the lower limbs increase neuropraxia and compression $[8,13]$. While a lower tourniquet pressure is safer than higher pressure, it may not provide a bloodless operative field. Optimal tourniquet pressure should be determined to balance safety and efficacy. In recent years, some investigators proposed that the tourniquet pressure setting should be personalized. Compression pressure on a pneumatic tourniquet's limb artery wall is different due to different physiological functions, such as systolic blood pressure, age, weight, limb circumference size, and muscle tissue thickness.

Setting the tourniquet pressure based on SBP or LOP allows us to use a personalized tourniquet pressure in each patient and is useful in optimizing tourniquet cuff pressures. The rationale behind inflating the tourniquet beyond the SBP, allowing a certain amount of safety margin, which added to the SBP ranges widely, from 100 to $250 \mathrm{mmHg}$ in the literature [30, 31]. LOP is the term that mean the lowest tourniquet pressure is required to cease the arterial blood flow into the extremity distal to the cuff. LOP can be determined automatically or manually by slow cuff inflation to pulse cessation with diagnostic equipment such as Doppler flowmeter or pulse oximeter[32-35]. Now, modern tourniquet systems permit an automated LOP estimation through a probe incorporated in the tourniquet system itself [4].

Following an analysis of the current literature, this work demonstrated a relative predominance of the advantages when a tourniquet is used with the personalized application. However, the present meta-analysis has several limitations: First, there are two methods for personalized tourniquets, including SBP and LOP. Because of the limited data, we were not able to evaluate one of them separately. We performed a sensitivity analysis on them and found that the conclusion is stable when removing one method. Second, the studies' comparability was complicated through the different measurement methods and follow-up examination time points; however, we have tried our best to evaluate results based on time points. Third, the tourniquet time, the time for loosening the tourniquet, and the cuff pressure used were also not uniform (see Tab. 1). Fourth, there are no worldwide uniform guidelines for performing total knee arthroplasty. Different surgical techniques (such as the selection of approach, methods of anesthesia, drainage patterns hemostasis, and anticoagulation regimens) were used in the individual studies.

\section{Conclusion}

In conclusion, personalized tourniquet inflation pressure provides a bloodless surgical field comparable to that of a conventional uniformed method with less pain intensity, thigh circumference, rate of thigh ecchymosis, higher HSS and better initial recovery knee flexion in total knee arthroplasty. Therefore, we recommend using personalized tourniquet inflation pressure during TKA. However, due to the limited comparability of the studies available, more longer follow-up period and overall higher quality RCTs are needed to confirm the present metaanalysis results.

\section{Abbreviations}

UTIP: uniform tourniquet inflation pressure; PTIP: personalized tourniquet inflation pressures; Cls: Confidence intervals; RCTs: Randomized controlled trials; RR: Risk ratio; OR: odds ratio; VMD: Weighted mean difference; TKA: Total knee arthroplasty; OA, osteoarthritis; RA, rheumatoid arthritis; BMI, body mass index; SBP, systolic blood pressure; LOP: Limb occlusion pressure;HSS, Hospital for Special Surgery ; ROM range of motion.

\section{Declarations}

\section{Ethics approval and consent to participate}

Not applicable.

\section{Consent for publication}

Not applicable.

\section{Availability of data and materials}

The datasets generated and analyzed during the current study are available from the corresponding author on reasonable request. 
Competing interests

The authors declare that they have no competing interests.

Funding

None.

Author contribution

Changjiao Sun, Xu Cai and Yonggang Zhou: Conceptualization Data curation; Formal analysis, Roles/Writing - original draft; Writing - review \& editing

Xin Yang and Qi Ma: Data collection; Investigation; Methodology;

Qi Ma and Peng Yui: Resources; Software

Xu Cai and Yonggang Zhou: (co-corresponding author): supervised the whole study

Conflict of Interest: The authors declare that they have no conflict of interest.

Acknowledgements

None

\section{References}

1. Noordin S, McEwen JA, Kragh JF, Jr., Eisen A, Masri BA: Surgical tourniquets in orthopaedics. J Bone Joint Surg Am 2009, 91(12):29582967.

2. Odinsson A, Finsen V: Tourniquet use and its complications in Norway. J Bone Joint Surg Br 2006, 88(8):1090-1092.

3. Olivecrona C, Blomfeldt R, Ponzer S, Stanford BR, Nilsson BY: Tourniquet cuff pressure and nerve injury in knee arthroplasty in a bloodless field: a neurophysiological study. Acta Orthop 2013, 84(2):159-164.

4. Olivecrona C, Ponzer S, Hamberg P, Blomfeldt R: Lower tourniquet cuff pressure reduces postoperative wound complications after total knee arthroplasty: a randomized controlled study of 164 patients. J Bone Joint Surg Am 2012, 94(24):2216-2221.

5. Berry DJ, Bozic KJ: Current practice patterns in primary hip and knee arthroplasty among members of the American Association of Hip and Knee Surgeons. J Arthroplasty 2010, 25(6 Suppl):2-4.

6. Parvizi J, Diaz-Ledezma C: Total knee replacement with the use of a tourniquet: more pros than cons. Bone Joint J 2013, 95-B(11 Suppl A):133-134.

7. Sadri A, Braithwaite IJ, Abdul-Jabar HB, Sarraf KM: Understanding of intra-operative tourniquets amongst orthopaedic surgeons and theatre staff-a questionnaire study. Ann R Coll Surg Engl2010, 92(3):243-245; quiz 241p following 245.

8. Sharma JP, Salhotra R: Tourniquets in orthopedic surgery. Indian J Orthop 2012, 46(4):377-383.

9. Yalcinkaya M, Sokucu S, Erdogan S, Kabukcuoglu YS: Tourniquet use in orthopedic surgery: a descriptive survey study among Turkish orthopedic surgeons and residents in Istanbul. Acta Orthop Traumatol Turc 2014, 48(5):483-490.

10. Vandenbussche E, Duranthon LD, Couturier M, Pidhorz L, Augereau B: The effect of tourniquet use in total knee arthroplasty. Int Orthop 2002, 26(5):306-309.

11. Mittal R, Ko V, Adie S, Naylor J, Dave J, Dave C, Harris IA, Hackett D, Ngo D, Dietsch S: Tourniquet application only during cement fixation in total knee arthroplasty: a double-blind, randomized controlled trial. ANZ J Surg 2012, 82(6):428-433.

12. Bould M, Freeman BJ, Pullyblank A, Newman JH: Blood loss in sequential bilateral total knee arthroplasty. J Arthroplasty 1998, 13(1):7779.

13. Wakankar HM, Nicholl JE, Koka R, D'Arcy JC: The tourniquet in total knee arthroplasty. A prospective, randomised study. J Bone Joint Surg Br1999, 81(1):30-33.

14. Barwell J, Anderson G, Hassan A, Rawlings I: The effects of early tourniquet release during total knee arthroplasty: a prospective randomized double-blind study. J Bone Joint Surg Br 1997, 79(2):265-268.

15. Geng J, Zhao P, Cheng J, Niu H, Zhang Y, Zhang Q, Xie P: Effect of lower tourniquet cuff pressure on reducing incision complications after total knee arthroplasty. Chinese Journal of Bone and Joint Injury 2014, 29(06):605-606. 
16. Lei Y, Li H, Zhang J, Mei B, Tao H: Personalized tourniquet pressure setting for total knee arthroplasty. Orthopedic Journal of China 2019, 27(15):1385-1389.

17. Si F: Application of individualized pressure value of inflatable tourniquet in knee arthroplasty. Shanghai Nursing Journa/2018, 18(02):45-47.

18. Wu Z, Yang P, Guo Y, Feng Q, Jin L: Study on individualized pressure nursing of pneumatic tourniquet during knee surface replacement. Jilin Medical Journal 2014, 35(33):7461-7463.

19. Zhang H, Chen M, Tai C: Application effect of individualized pressure value of inflatable tourniquet in total knee arthroplasty. Anhui Medical Journal 2016, 37(10):1292-1293.

20. Zhou J, Hu W, Hu S, Hu B, Liu S, Xiong L, Qian R: Application of personalized tourniquet pressure in primary total knee arthroplasty. J Clin Rehabil Tis Eng Res 2019, 23(20):3136-3142.

21. Ishii Y, Matsuda Y: Effect of tourniquet pressure on perioperative blood loss associated with cementless total knee arthroplasty: a prospective, randomized study. J Arthroplasty 2005, 20(3):325-330.

22. de Souza Leao MG, Neta GP, Coutinho LI, da Silva TM, Ferreira YM, Dias WR: Comparative analysis of pain in patients who underwent total knee replacement regarding the tourniquet pressure. Rev Bras Ortop 2016, 51(6):672-679.

23. Unver B, Karatosun V, Tuncali B: Effects of tourniquet pressure on rehabilitation outcomes in patients undergoing total knee arthroplasty. Orthop Nurs 2013, 32(4):217-222.

24. Anna P, Jinfu H, Yanling L: Influence of personalized electric pneumatic tourniquet pressure setting on total knee arthroplasty. Chin J Mod Drug App/2019, 13(22):80-81.

25. Tao J, Yao H, Peng H, Xu H: Application of individualized electric pneumatic tourniquet pressure in total knee arthroplasty. Modern Nurse 2018, 25(11):134-135.

26. Yang Y, Gao X, Yu L, Liu H, Wu H, Yao C: Research of the pressure value setting of tourniquet based on blood oxygen monitor in elderly patients with total knee arthroplasty. China Medical Equipment 2020, 17(10):132-135.

27. Zhang L, Ju R: Influence of different pressure parameters of pneumatic tourniquet on patients undergoing knee arthroplasty. Practical Journal of Medicine \& Pharmacy 2021, 38(01):57-59.

28. Worland RL, Arredondo J, Angles F, Lopez-Jimenez F, Jessup DE: Thigh pain following tourniquet application in simultaneous bilateral total knee replacement arthroplasty. J Arthroplasty 1997, 12(8):848-852.

29. Recommended practices for use of the pneumatic tourniquet. Aorn j 2002, 75(2):379-382, 384-376.

30. Clarke MT, Longstaff L, Edwards D, Rushton N: Tourniquet-induced wound hypoxia after total knee replacement. J Bone Joint Surg Br 2001, 83(1):40-44.

31. Tetro AM, Rudan JF: The effects of a pneumatic tourniquet on blood loss in total knee arthroplasty. Can J Surg 2001, 44(1):33-38.

32. Masri BA, Day B, Younger AS, Jeyasurya J: Technique for Measuring Limb Occlusion Pressure that Facilitates Personalized Tourniquet Systems: A Randomized Trial. J Med Biol Eng 2016, 36(5):644-650.

33. McLaren AC, Rorabeck CH: The pressure distribution under tourniquets. J Bone Joint Surg Am 1985, 67(3):433-438.

34. Reid HS, Camp RA, Jacob WH: Tourniquet hemostasis. A clinical study. Clin Orthop Relat Res 1983(177):230-234.

35. Younger AS, Manzary M, Wing KJ, Stothers K: Automated cuff occlusion pressure effect on quality of operative fields in foot and ankle surgery: a randomized prospective study. Foot Ankle Int 2011, 32(3):239-243.

\section{Tables}

Table 1 The detailed baseline characteristics information 


\begin{tabular}{|c|c|c|c|c|c|c|c|c|}
\hline Author/year & Patients & Knees & $\begin{array}{l}\text { Mean } \\
\text { age(years) }\end{array}$ & $\begin{array}{l}\text { Female } \\
\text { gender }(\mathbb{X})\end{array}$ & BMI & Diagnosis & Prothesis & Anesthesia \\
\hline Ishii 2005 & $29 / 28$ & $30 / 30$ & $71 / 68$ & $93.1 / 85.7$ & $25.5 / 26.6$ & 290A,1RA/270A,3RA & $\begin{array}{l}\text { cementless TKA } \\
\text { with New Jersey } \\
\text { LCS }\end{array}$ & Spinal \\
\hline Unver 2013 & $17 / 21$ & $17 / 21$ & $68 / 67.3$ & $82.4 / 85.7$ & $30.8 / 32$ & $170 A / 210 A$ & $\begin{array}{l}\text { (Nexgen; } \\
\text { Zimmer, } \\
\text { Warsaw, IN). }\end{array}$ & General \\
\hline $\begin{array}{l}\text { De Souza } \\
\text { Leão } 2016\end{array}$ & $30 / 30$ & $30 / 30$ & $66 / 65.4$ & 73.3/76.7 & NA & $300 A / 300 A$ & $\begin{array}{l}\text { Modular III® } \\
\text { (MDT, Rio Claro, } \\
\text { SP, Brazil), }\end{array}$ & Spinal \\
\hline Geng 2014 & $61 / 60$ & $61 / 60$ & NA & NA & NA & $610 A / 600 A$ & NA & NA \\
\hline Lei 2019 & $36 / 35$ & $36 / 35$ & $67.42 / 68.86$ & $80.6 / 80$ & $24.67 / 24.84$ & $360 A / 350 A$ & $\begin{array}{l}\text { CR Gemi MK } \\
\text { (LINK, Germany) }\end{array}$ & General \\
\hline Si 2018 & $88 / 82$ & $88 / 82$ & NA & NA & NA & 88 OA/82 OA & NA & General \\
\hline Wu 2014 & $30 / 30$ & $30 / 30$ & $65.97 / 65.67$ & NA & $23.26 / 23.74$ & $30 \mathrm{OA} / 300 \mathrm{~A}$ & NA & Spinal \\
\hline $\begin{array}{l}\text { Zhang } \\
2016\end{array}$ & $80 / 80$ & $80 / 80$ & NA & NA & NA & $80 \mathrm{OA} / 800 \mathrm{~A}$ & NA & General \\
\hline zhou 2019 & $50 / 50$ & $50 / 50$ & $67 / 65.8$ & $52 / 54$ & $22.9 / 23$ & $50 \mathrm{OA} / 500 \mathrm{~A}$ & A3(AKMEDICAL) & General \\
\hline Pan 2019 & $50 / 50$ & $50 / 50$ & $66.35 / 65.43$ & $64 / 58$ & NA & $50 \mathrm{OA} / 500 \mathrm{~A}$ & NA & Spinal \\
\hline Yang 2020 & $50 / 50$ & $50 / 50$ & $69.44 / 70.35$ & $40 / 30$ & NA & NA & NA & NA \\
\hline $\begin{array}{l}\text { Zhang } \\
2021\end{array}$ & $42 / 42$ & $42 / 42$ & $58.91 / 59.89$ & $40.5 / 38.1$ & NA & $42 \mathrm{OA} / 42 \mathrm{OA}$ & NA & Spinal \\
\hline Tao 2018 & $40 / 40$ & $40 / 40$ & $63.5 / 64.3$ & $62.5 / 60$ & NA & $40 \mathrm{OA} / 400 \mathrm{~A}$ & NA & Spinal \\
\hline
\end{tabular}

The detailed baseline characteristics information, including the number of TKAs, age, gender, BMI, diagnosis, prothesis, anesthesia of two groups.

Table 2 The tourniquet intervention information 


\begin{tabular}{|c|c|c|c|c|c|}
\hline \multirow[b]{2}{*}{ Author/year } & \multirow[b]{2}{*}{$\begin{array}{l}\text { Operation } \\
\text { time(min) }\end{array}$} & \multicolumn{4}{|c|}{ Personalized tourniquet pressurel/Conventional tourniquet pressure } \\
\hline & & $\begin{array}{l}\text { Mean } \\
\text { tourniquet } \\
\text { time(min) }\end{array}$ & $\begin{array}{l}\text { Mean Inflation } \\
\text { pressure(mmHg) }\end{array}$ & $\begin{array}{l}\text { Practices of } \\
\text { tourniquet pressure }\end{array}$ & The time for loosening the tourniquet \\
\hline Ishii 2005 & $71 / 72$ & $48 / 50$ & $238 / 350$ & $\begin{array}{l}100 \mathrm{~mm} \mathrm{Hg} \text { above } \\
\text { SBP/350mmHg }\end{array}$ & Before the incision was closed \\
\hline Unver 2013 & NA & $60 / 58.3$ & $169.7 / 304.7$ & $\mathrm{AOP} / 300 \mathrm{mmHg}$ & $\begin{array}{l}\text { After the application of a wool and } \\
\text { crepe bandage to the limb. }\end{array}$ \\
\hline De Souza Leã & o 2016 & $118 / 110$ & NA & $\begin{array}{l}100 \mathrm{~mm} \mathrm{Hg} \text { above } \\
\text { SBP/350mmHg }\end{array}$ & After Robert Jones dressing was made \\
\hline Geng 2014 & NA & NA & $245 / 250$ & $\mathrm{LOP} / 250 \mathrm{mmHg}$ & NA \\
\hline Lei 2019 & NA & $55.79 / 57.23$ & $181.72 / 270$ & $\mathrm{LOP} / 270 \mathrm{mmHg}$ & $\begin{array}{l}\text { After the application of a bandage to } \\
\text { the limb. }\end{array}$ \\
\hline Si 2018 & & $59 / 59$ & $340.425 / 487.5$ & $\mathrm{LOP} / 487.5 \mathrm{mmHg}$ & $\begin{array}{l}\text { After the application of a bandage to } \\
\text { the limb. }\end{array}$ \\
\hline Wu 2014 & NA & $81.77 / 81.23$ & $360.28 / 500$ & $\mathrm{LOP} / 500 \mathrm{mmHg}$ & NA \\
\hline $\begin{array}{l}\text { Zhang } \\
2016\end{array}$ & NA & $59.61 / 59.84$ & $333 / 487.5$ & $\mathrm{LOP} / 487.5 \mathrm{mmHg}$ & $\begin{array}{l}\text { After the application of a bandage to } \\
\text { the limb. }\end{array}$ \\
\hline zhou 2019 & NA & NA & NA & $\mathrm{LOP} / 525 \mathrm{mmHg}$ & $\begin{array}{l}\text { After the application of a bandage to } \\
\text { the limb. }\end{array}$ \\
\hline Pan 2019 & NA & NA & NA & $\begin{array}{l}112.5 \mathrm{mmHg} \text { above } \\
\text { SBP / } 450 \mathrm{mmHg}\end{array}$ & NA \\
\hline Yang 2020 & NA & NA & $413.83 / 450$ & $\mathrm{LOP} / 450 \mathrm{mmHg}$ & NA \\
\hline $\begin{array}{l}\text { Zhang } \\
2021\end{array}$ & NA & NA & NA & $\begin{array}{l}112.5 \mathrm{mmHg} \text { above } \\
\text { SBP / } 450 \mathrm{mmHg}\end{array}$ & $\begin{array}{l}\text { After the application of a bandage to } \\
\text { the limb. }\end{array}$ \\
\hline Taо 2018 & NA & NA & NA & $\begin{array}{l}150 \mathrm{mmHg} \text { above } \\
\text { SBP / } 450 \mathrm{mmHg}\end{array}$ & $\begin{array}{l}\text { After the application of a bandage to } \\
\text { the limb }\end{array}$ \\
\hline
\end{tabular}

The tourniquet intervention information including the operation time, Mean tourniquet time, mean inflation pressure, practices of tourniquet pressure, the time for loosening the tourniquet of two groups.

Figures 


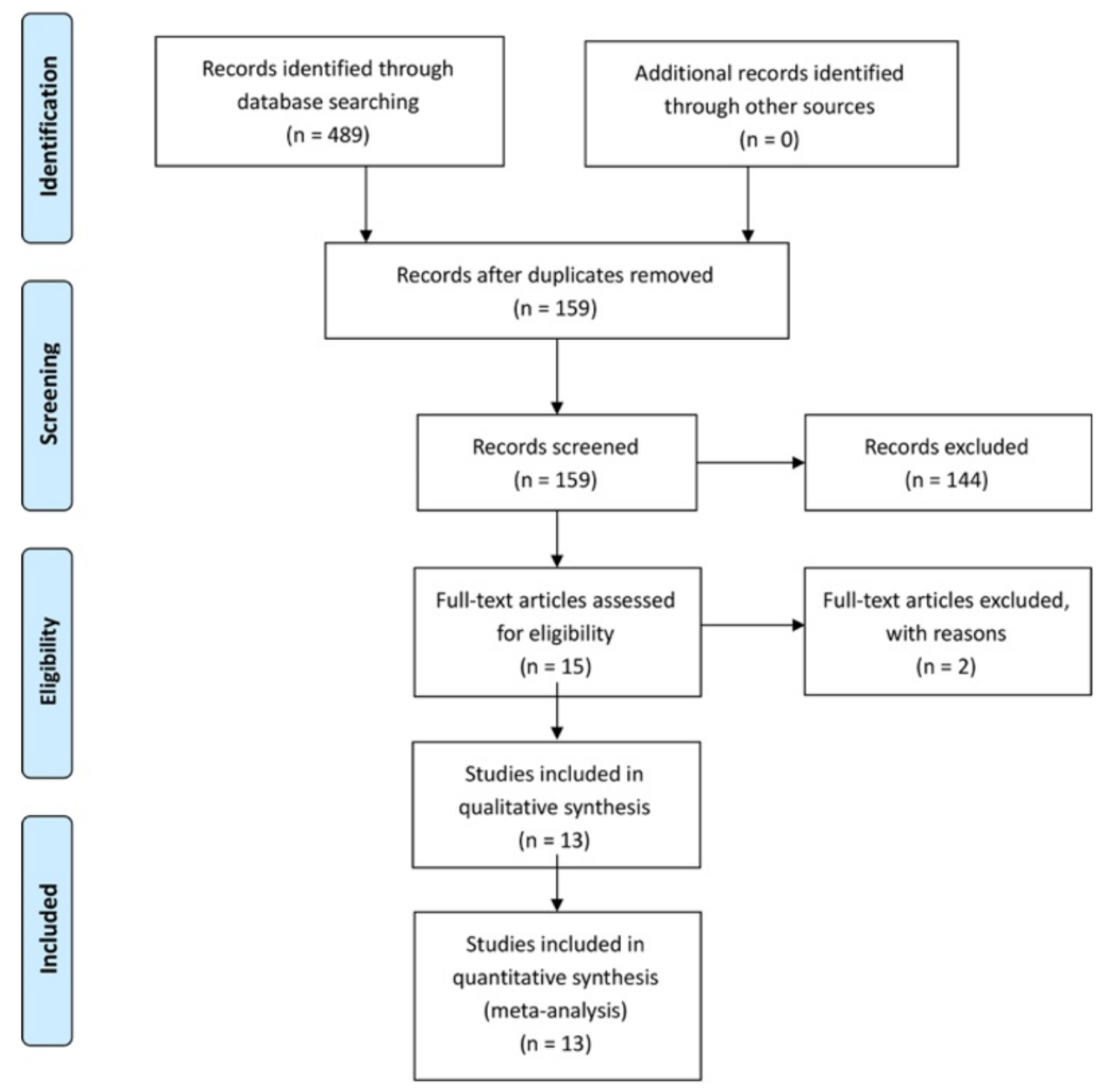

\section{Figure 1}

The search results and selection procedure. The literature search identified 489 citations. Of these, we removed 330 duplicates. Upon reviewing the titles and abstracts of the 159 remaining articles, we excluded 144 papers according to the inclusion criteria and retrieved the full text of 13 articles. Finally, we identified 1204 TKAs (1201 patients) assessed in 13 randomized controlled trials. 


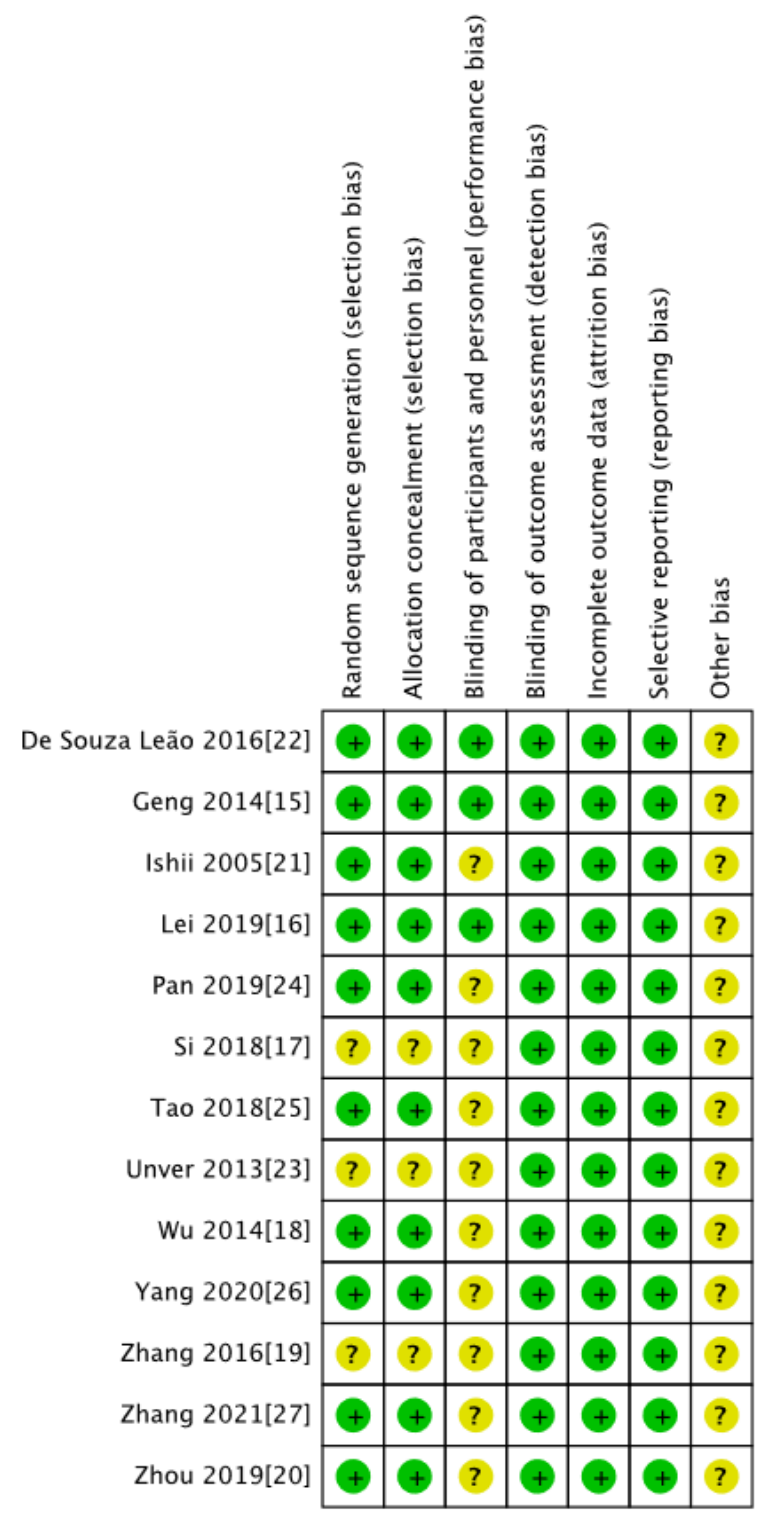

\section{Figure 2}

The risk of bias summary for RCTs +:no bias; :-bias; ?:bias unknown. The correct randomization and sufficient allocation concealment were adequately described in ten studies. The blinding of outcome assessment was described in 13 studies, and the blinding of participants and personnel was described in three studies. Each study retained complete outcome data and avoided selective reporting. Other potential biases of all studies can't be ignored. Therefore, we rated them as having an unclear risk of other bias. As a result, the included studies' overall quality was considered adequate 
Random sequence generation (selection bias)

Allocation concealment (selection bias)

Blinding of participants and personnel (performance bias)

Blinding of outcome assessment (detection bias)

Incomplete outcome data (attrition bias)

Selective reporting (reporting bias)

Other bias
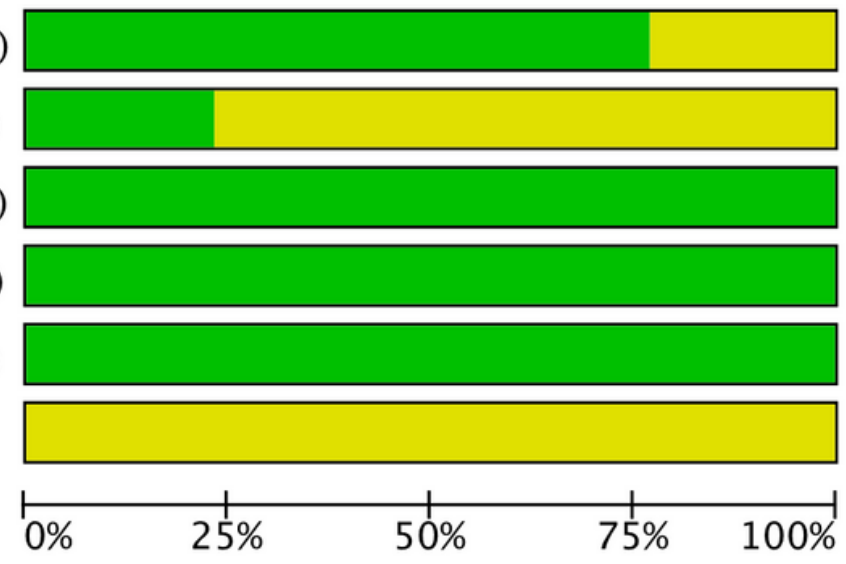

\section{Low risk of bias $\quad \square$ Unclear risk of bias}

High risk of bias

\section{Figure 3}

The risk of bias graph. The overall quality of the studies was considered adequate.

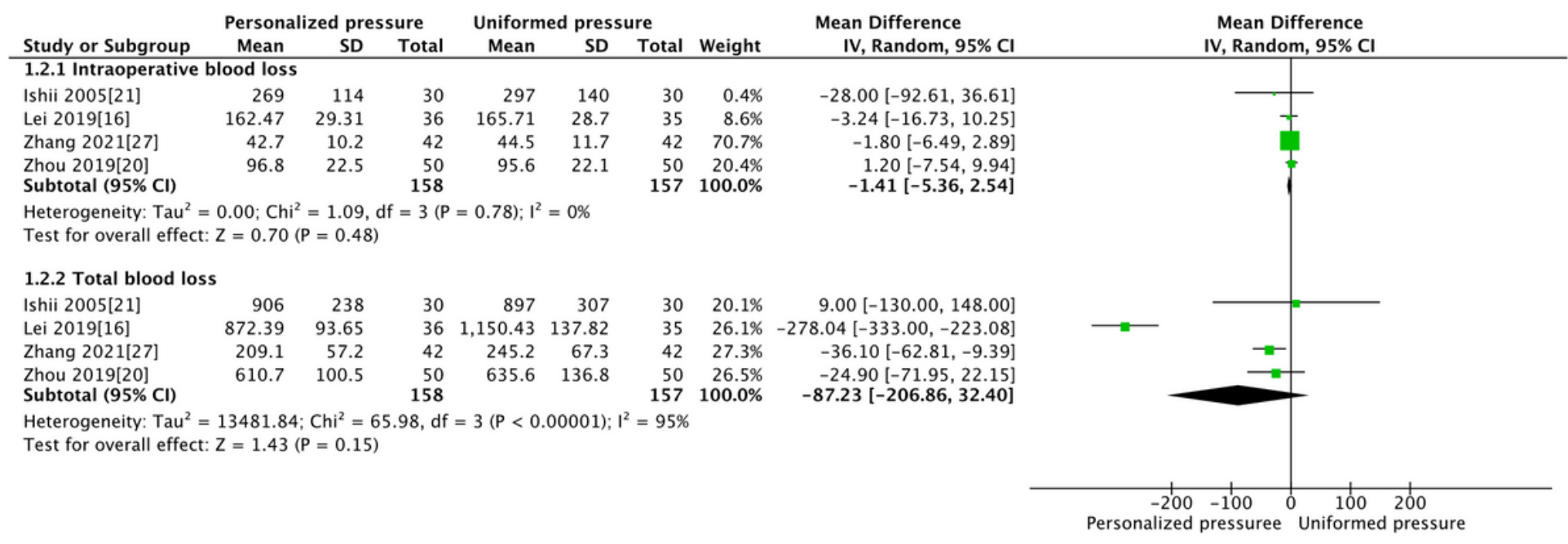

\section{Figure 4}

Pooled analysis of blood loss between the PTIP group and the UTIP group. Patients in both groups experienced similar intraoperative blood loss $(\mathrm{MD}=-1.41,95 \% \mathrm{Cl}[-5.36,2.54], \mathrm{P}=0.48)$ and total blood loss $(\mathrm{MD}=-87.23,95 \% \mathrm{Cl}[-206.86,32.40], \mathrm{P}=0.15)$. 


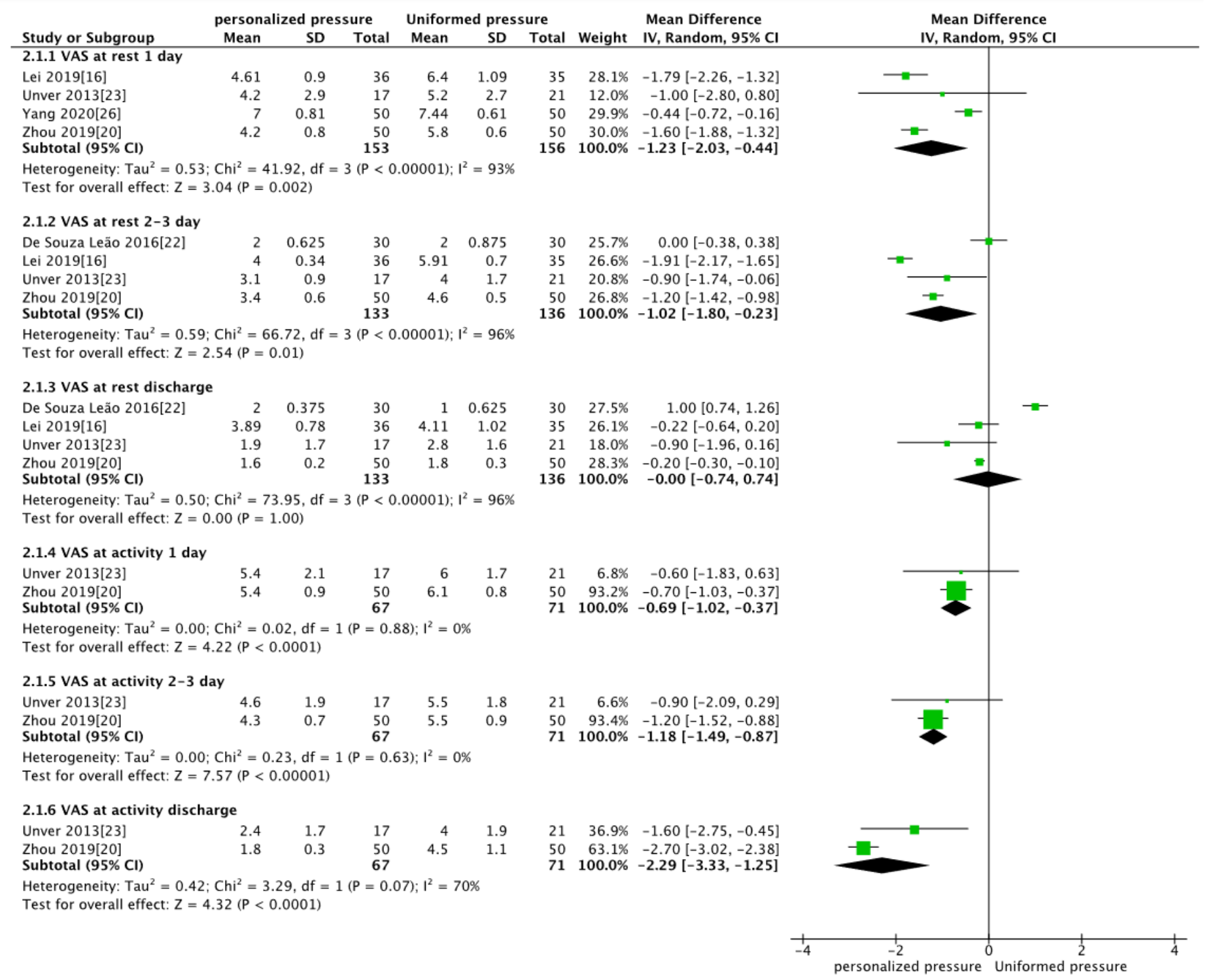

\section{Figure 5}

Pooled analysis of VAS between PTIP group and UTIP group. In personalized pressure group, there is a significantly lower VAS at rest 1 day after operation( $\mathrm{MD}=-1.23,95 \% \mathrm{Cl}[-2.03,-0.44], \mathrm{P}=0.002), 2-3$ days after operation( $\mathrm{MD}=-1.02,95 \% \mathrm{Cl}[-1.8,-0.23], \mathrm{P}=0.01)$ and lower VAS at activity 1 day after operation( $M D=-0.69,95 \% \mathrm{Cl}[-1.02,-0.37], P \otimes 0.0001), 2-3$ days after operation (MD=-1.18, 95\% Cl [-1.49,-0.87], Pख0.00001 )and discharge $(\mathrm{MD}=-2.29,95 \% \mathrm{Cl}[-3.33,-1.25], \mathrm{P} \otimes 0.0001)$. Patients in both groups experienced similar VAS at rest when discharge from hospital (MD=-0.00, 95\% Cl [-0.74,0.74], $\mathrm{P}=1.0)$. 


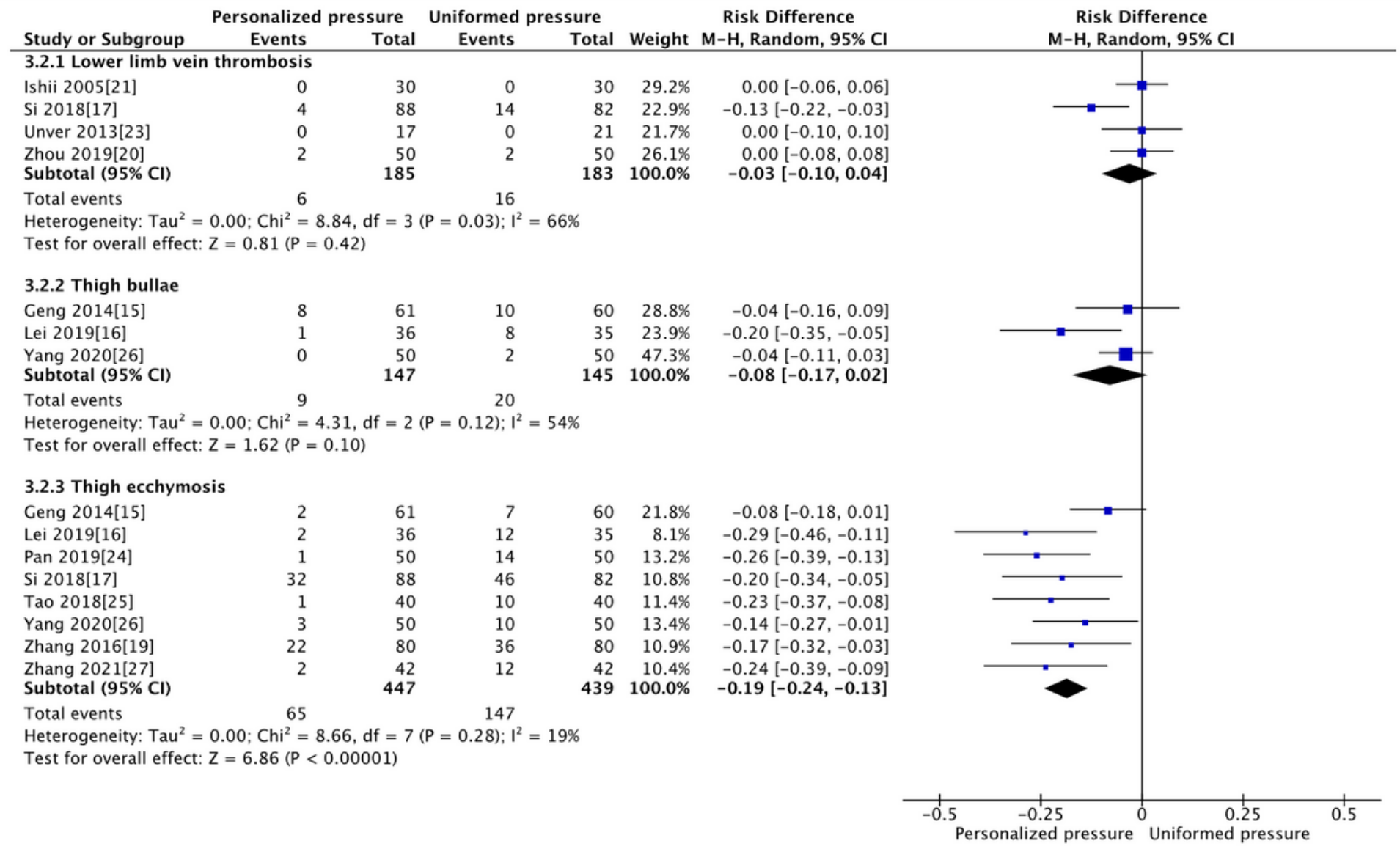

\section{Figure 6}

Pooled analysis of complication rates between PTIP group and UTIP group. Both groups experienced similar rates of lower limb vein thrombosis $(\mathrm{MD}=-0.03,95 \% \mathrm{Cl}[-0.1,0.04], \mathrm{P}=0.42)$ and thigh bullae $(\mathrm{MD}=-0.08,95 \% \mathrm{Cl}[-0.17,0.02], \mathrm{P}=0.1)$. There is a significantly lower rate of thigh ecchymosis (MD=-0.19, 95\% Cl [-0.24,-0.13], $\mathrm{P} \otimes 0.00001)$ in patients with personalized pressure group.

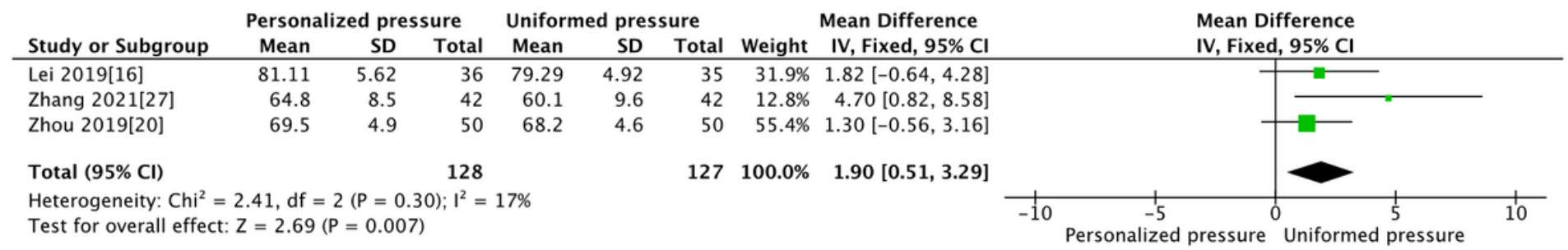

\section{Figure 7}

Pooled analysis of HSS between PTIP group and UTIP group. In personalized pressure group, there is a significantly higher HSS (MD=1.90, $95 \% \mathrm{Cl}[0.51,3.29], \mathrm{P}=0.007)$

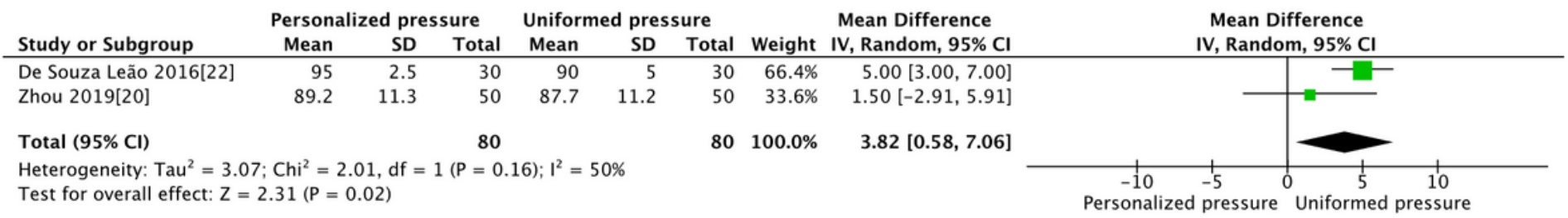

Figure 8 
Pooled analysis of ROM between PTIP group and UTIP group. There is significantly better knee ROM (MD=3.82, 95\% Cl [0.58,7.06], P=0.02) in patients with personalized pressure group.

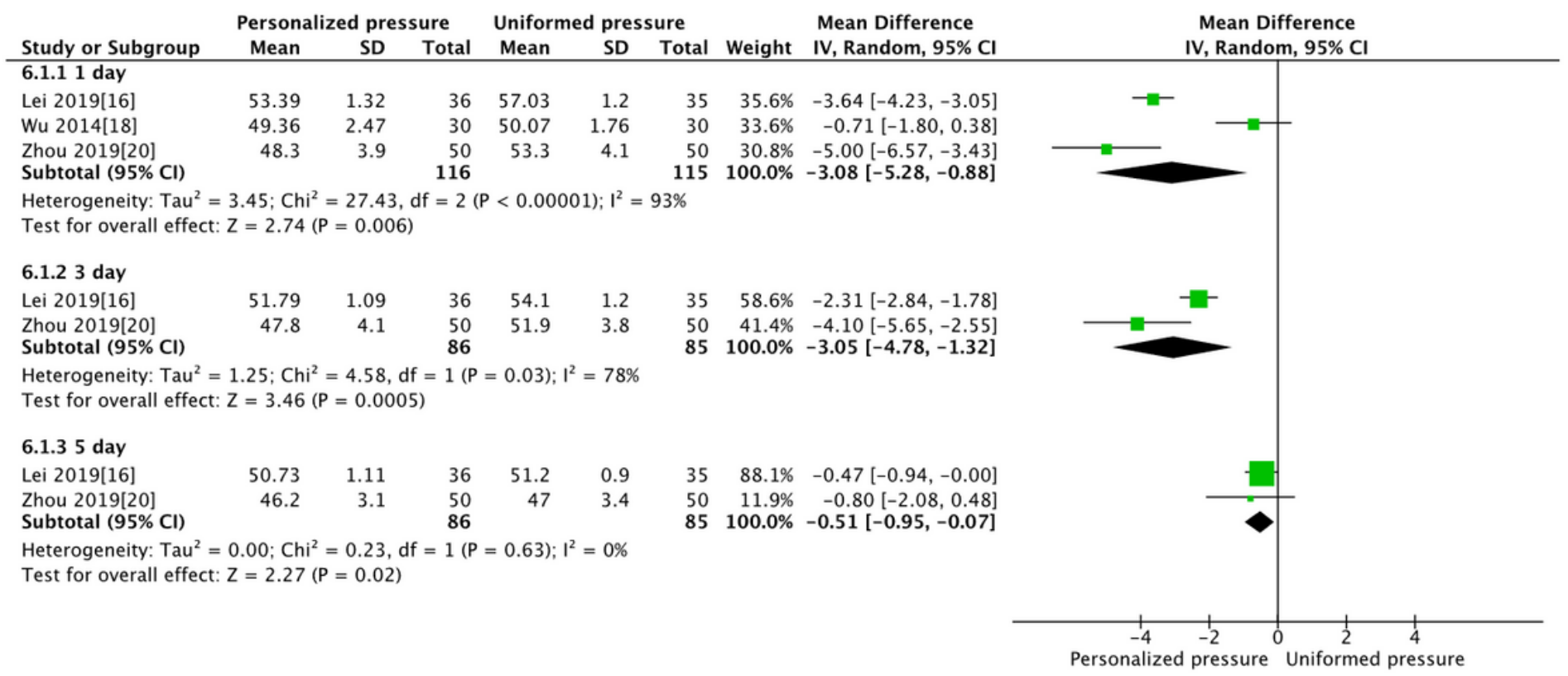

\section{Figure 9}

Pooled analysis of thigh circumference between PTIP group and UTIP group. Thigh circumference is significantly shorter 1 day after operation (MD=-3.08, 95\% Cl [-5.28,-0.88], $\mathrm{P}=0.006)$,3day after operation( $\mathrm{MD}=-3.05,95 \% \mathrm{Cl}[-4.78,-1.32], \mathrm{P}=0.0005)$ and 5 day after operation $(\mathrm{MD}=-0.51,95 \% \mathrm{Cl}[-0.95,-0.07], \mathrm{P}=0.02)$ in patients with personalized pressure group. 